\title{
Trends in Research Literature Describing Dysphagia in Motor Neuron Diseases (MND): A Scoping Review
}

\author{
Ashley A. Waito, MSc ${ }^{1,2}$, Teresa J. Valenzano, MSc, MHSc ${ }^{1,2}$, Melanie Peladeau-Pigeon, \\ MHSc $^{2}$, and Catriona M. Steele, PhD ${ }^{1,2,3}$ \\ ${ }^{1}$ University of Toronto, Rehabilitation Sciences Institute, Toronto, ON, Canada \\ ${ }^{2}$ Toronto Rehabilitation Institute - University Health Network, Toronto, ON, Canada \\ ${ }^{3}$ Bloorview Research Institute, Toronto, ON, Canada
}

\section{Abstract}

Dysphagia in motor neuron diseases (MNDs) is highly complex, affecting all stages of swallowing and leading to impaired swallowing safety and efficiency. In order to explore the degree to which research is capturing the symptom of dysphagia in MND, we conducted a scoping review of the existing literature. The primary aims of this review were to identify common themes within the literature on dysphagia in MND, explore patterns and trends in research focus, and identify if any imbalances exist between the research themes related to dysphagia description and management.

Methods-A comprehensive search strategy yielded 1690 unique articles for review. Following relevance screening, a total of 157 articles were included in the synthesis. Relevant data and keywords were extracted from each article and grouped into themes. Frequency estimates were calculated for each theme to identify trends across research literature.

Results-Swallowing impairment in MNDs is described in a variety of ways across current research. The most commonly reported theme was Aspiration/Penetration, mentioned in $73.2 \%$ of all included articles; a significant imbalance was identified between reports of swallowing safety and efficiency ( $\mathrm{p}=0.008$ ). The most frequently reported theme related to dysphagia management was Enteral Nutrition, and very few studies have reported on the efficacy of Rehabilitation/ Compensatory recommendations.

Conclusions-It is suggested that researchers and clinicians remain mindful of imbalances and gaps in research, and aim to characterize dysphagia in MNDs in a comprehensive manner. Further research investigating discrete, measureable changes in swallowing pathophysiology would be beneficial to delineate the key factors contributing to impaired swallowing safety and efficiency.

\section{Keywords}

deglutition; deglutition disorders; Amyotrophic Lateral Sclerosis; motor neuron disease; scoping review

Reprint Address: Ashley A. Waito, Toronto Rehabilitation Institute - University Health Network, 550 University Avenue, \# 12-019 (H2), Toronto, ON, M5G 2A2, Canada, 416-597-3422 ext. 7812.

Institutional Address:

Toronto Rehabilitation Institute - University Health Network, 550 University Avenue, \# 12-101, Toronto, ON, M5G 2A2, Canada

Conflicts of Interest: The authors have no conflicts of interest to disclose. 


\section{INTRODUCTION}

Motor neuron disease (MND) represents a class of neurodegenerative disorders

characterized by progressive deterioration of motor neurons, leading to weakness, spasticity, and atrophy of the innervated muscles [1]. In addition to classic Amyotrophic Lateral Sclerosis (ALS), which affects upper and lower motor neurons of the corticobulbar and spinal tracts, the International Statistical Classification of Diseases and Related Health Problems (ICD-10) recognizes three additional subtypes of MND, based on differing patterns of motor neuron involvement (i.e., upper vs. lower motor neurons), and muscle involvement (i.e., spinal vs. bulbar). These subtypes include progressive bulbar palsy, primary lateral sclerosis, and progressive muscular atrophy [2] (summarized in Table 1). Progressive bulbar palsy (PBP) leads to degeneration of upper and lower motor neurons, selectively affecting bulbar musculature, and has a relatively shorter predicted survival. Primary lateral sclerosis (PLS) is diagnosed when only upper motor neurons are affected. In contrast, progressive muscular atrophy (PMA) affects lower motor neurons only, and primarily involves spinal muscle groups. Disease progression is generally slower and longer for individuals with PMA and PLS, compared to classic ALS or PBP. Due to these differences in motor neuron and muscle involvement, there is inherent variability between the subtypes of MND. Still, the diagnoses are not mutually exclusive, as each has the potential to be relabeled as classic ALS if additional pathophysiological signs develop [3-8].

At this time, there is no cure for MND, and symptomatic management is the primary course of treatment [9-12]. This highlights the importance for researchers and clinicians to identify and explore mechanisms of impairment early, in order to provide management options in an appropriate and timely manner.

Dysphagia (i.e., swallowing impairment), is one of the most common and devastating symptoms affecting individuals with MND, particularly when bulbar muscles are involved [7], as in PBP, PLS and ALS. Dysphagia is a serious medical complication that places an affected individual at risk for dehydration, malnutrition, and pneumonia secondary to aspiration (i.e., material entering the airway below the level of the vocal folds). Estimates of dysphagia prevalence in patients with ALS, for example, range from 60-86\% [13,14], with additional sources suggesting that almost all patients with ALS will eventually develop dysphagia to some degree $[15,16]$. Although prevalence rates of dysphagia among other subtypes of MND are not as clearly defined, swallowing problems have been identified in all four subtypes [16-19]. In a study by Leighton et al. (1994), swallowing problems were identified in $89 \%$ of included participants with PBP, $45 \%$ of participants with PMA, and $29 \%$ of participants with classic ALS. Signs and symptoms of dysphagia in patients with MND may include loss of food and liquids out of the mouth, premature entry of liquids into the pharynx prior to swallowing, difficulty clearing bolus material from the oral cavity and pharynx during swallowing (i.e., post-swallow residue), frequent episodes of coughing/ choking on food or liquids, and esophageal dysmotility [7]. As the disease progresses, individuals with MND ultimately experience a worsening of symptoms, affecting quality of life and placing increased demands on the healthcare system to evaluate and manage symptoms appropriately. When dysphagia is paired with respiratory impairment, the risk of 
developing aspiration pneumonia increases significantly; for patients with ALS, bronchoand aspiration pneumonia are leading causes of death [20].

Although research investigating the presentation of dysphagia across the MNDs has provided insight into its prevalence and clinical presentation, there is an ongoing need for additional research to delineate the key physiological mechanisms contributing to functional swallowing impairment, and determine appropriate rationales to recommend or refine existing management strategies. Further, given the variability of dysphagia within and between MND types, and as it evolves throughout disease progression, it is important for research to capture and investigate the full range of swallowing challenges experienced by individuals with MND, and delineate the factors that affect presentation of dysphagia between the four MND subtypes.

We conducted a scoping review in order to summarize the profile of existing research on dysphagia across the subtypes of MND, and to identify gaps in the existing literature. We followed current guidelines for scoping review methodology [21-24] to address the following research questions:

1. How does the current research literature describe swallowing physiology and dysphagia in MND?

2. How is swallowing physiology and function in individuals with MND being measured and reported?

3. What recommendations are currently being made for the management of dysphagia in MND?

We kept the search strategy broad to include all four subtypes of MND, due to differences in terminology between different geographical regions (e.g., "Motor Neurone Disease" commonly used synonymously with ALS in Europe), fluidity between subtypes (e.g., PBP typically progresses to classic ALS with onset of spinal muscle involvement), and shared pathophysiology of motor neuron cell death captured under ICD-10 Code 12.2.

\section{METHODS}

\section{Search Strategy}

We conducted an initial literature search in October 2015, and updated the search on February $7^{\text {th }}, 2017$. Forty-seven terms related to dysphagia and MND were translated across six databases (Medline, EMBASE, CINAHL, SpeechBite, CENTRAL, Pubmed) by a qualified research librarian. The entire search strategy can be found in Appendix A. Retrieved citations were imported into EndNote $\mathrm{X} 5{ }^{\circledR}$ software for removal of duplicates, data management and storage. Overall, the search yielded a total of 1691 unique articles for relevance screening.

\section{Relevance Screening}

During initial inclusion screening, titles and abstracts were copied into a Microsoft Excel spreadsheet, labelled by EndNote ${ }^{\circledR}$ record number. Title and abstract screening was completed by two independent raters using a shared relevance screening form, with $20 \%$ 
duplication for interrater comparison. At this stage, raters were blinded to the publishing journal and author names to minimize bias related to recognition of familiar authors' names.

Following title and abstract screening, full-text articles were reviewed by the first author for final inclusion in the planned qualitative synthesis. Articles were excluded if they: (1) reported on a population that was not a subtype of MND, under ICD-10 code G12.2; (2) failed to describe swallowing, dysphagia, or dysphagia management; (3) were not a peerreviewed journal article; or (4) were not available in English.

\section{Data Extraction \& Synthesis}

Thematic analysis was completed in two steps: theme identification and tabulation. To identify themes within the dataset, key words and findings were extracted from each included article and summarized in a Microsoft Excel spreadsheet, separating distinctive keywords and phrases using consistent notation (e.g., "Individuals with MND experience coughing during meals, frequent episodes of aspiration, and may require nutritional support via $P E G$ tube" $\rightarrow$ EXTRACTED $\rightarrow$ [aspiration; coughing during meals; PEG]). The resulting data were filtered to identify unique keywords, which were then manually grouped into related themes and sub-themes. The resulting themes were reviewed iteratively by both raters for feedback and clarification, until consensus was reached.

Theme headings were used to create a form to count the occurrence of each theme within each article. This step was necessary to calculate the frequency with which each theme occurred across the entire set of included articles, and to control for cases where the same theme was noted more than once in the same article, using slightly different terminology (e.g., [aspiration]+[choking] occurring in the same article would be counted once in the "Aspiration/Penetration" theme). Tabulation was completed by two independent raters, with $20 \%$ duplication for interrater comparison. Field codes were used during tabulation to delineate original research findings, either obtained from clinical observations (i.e., clinical findings: $[\mathrm{CF}]$ ) or instrumental assessment (i.e., instrumental findings: [IF]), for later comparison against themes that were identified as coming from secondary sources (i.e., review: $[R])$. Following tabulation, proportions were calculated for themes and sub-themes within Excel.

\section{RESULTS}

Following relevance review, a total of 157 full-text articles were included in the qualitative analysis for theme identification and appraisal of research trends.

\section{Interrater Agreement Statistics}

Percent agreement was calculated for article inclusion/exclusion decisions during title and abstract screening, and for the tabulation of theme occurrence during review. Interrater agreement during initial title and abstract relevance screening was $87 \%$; articles in disagreement were automatically included in detailed full-text review. Overall, substantial agreement was achieved during theme tabulation, calculated using the Kappa statistic [25] (summarized in Table 2). 


\section{Descriptive Statistics}

The majority of articles originated from the United States (32.5\%) and United Kingdom $(21.7 \%)$ (see Table 3 ). The search yielded a greater number of original, non-review articles (78.3\%), than secondary source review articles (21.7\%). The most commonly discussed type of MND was ALS (69.4\%). See Table 3 for a full summary of the included articles, and countries of origin. A list of all included articles can be found in Appendix B.

\section{Themes - Dysphagia Description}

Descriptions of dysphagia varied widely across research articles. All primary themes are shown in Figure 2, in order of frequency. The following primary themes were identified at least 30\% of the articles reviewed ( $\mathrm{N}=157)$ : Aspiration/Penetration (73.2\%), Consequences of Dysphagia (66.2\%) (e.g., prolonged mealtimes, aspiration pneumonia), Changes in Muscle Tone contributing to dysphagia (58.6\%) (e.g., tongue weakness, hyper-I hyporeflexia), Oral Phase Difficulties (55.4\%), Pharyngeal Phase Difficulties (55.4\%), measures of Functional Swallowing Ability (36.3\%) (e.g., diet tolerance, reduced swallowing capacity), and issues with Secretion Management (35.7\%) (e.g., sialorrhea, thick secretions). Other themes that emerged less frequently (i.e., in $<30 \%$ of all 157 articles) included: Laryngeal/Respiratory Function in relation to dysphagia (27.4\%), changes in Sensory Function (12.1\%), Esophageal Difficulties (10.2\%), and Cortical/Histological findings related to swallowing or dysphagia in individuals with MND (5.7\%). Of note, there was significant overlap between themes, as more than one theme was often discussed in the same article.

\section{Swallow Physiology and Function in MND}

Sub-themes related to swallowing physiology and function were identified within the Oral and Pharyngeal Phase Impairment themes. The most commonly noted concern within the oral phase was impaired bolus preparation and bolus propulsion, reported in $27.4 \%$ (i.e., 43/157) of all included articles. Additional oral phase sub-themes included: Impaired Chewing, Poor Oral Containment (anteriorly or posteriorly), Oral Residue, Impaired Tongue Movement during the swallow, and Changes in Oral Timing/Coordination. By contrast, Impaired Pharyngeal Timing/Coordination (e.g., delayed swallow onset) was most commonly discussed in reference to Pharyngeal Phase Difficulties, occurring in $29.3 \%$ of all included articles (i.e., 46/157). Keywords related to Aspiration/Penetration were grouped independently from specific phases of swallowing, as it was not always clear when a reported event occurred (i.e., before, during, or after the swallow), and the proportion of articles discussing this theme greatly outnumbered all other themes.

\section{Instrumental Assessment}

Of all original research articles (i.e., $n=123$; excluding secondary source review articles), 71 articles $(57.7 \%)$ used instrumental assessment to support their descriptions of dysphagia, summarized in Table 3. The majority of studies used a form of radiographic imaging (39.8\%) or endoscopy (14.6\%), and although $64.8 \%$ of studies (i.e., 46/71) used only one tool, $38.0 \%$ (i.e., 27/71) of studies with instrumental assessment methods used two or more tools simultaneously (most commonly, videofluoroscopy + manometry $(\mathrm{n}=8)$; 
videofluoroscopy + endoscopy $(n=2)$; videofluoroscopy + manometry + endoscopy $(n=3))$. In terms of analysis, observations from instrumental assessment were most often descriptive in nature (e.g., "reduced hyolaryngeal elevation"), rather than reporting quantitative measurements of physiology and function. Instrumental assessment tools were used more frequently in original research articles which specifically reported findings related to Aspiration/Penetration (62.5\%; i.e., 35/56), Oral Phase Difficulties (66.0\%; i.e., 35/53) or Pharyngeal Phase Difficulties (91.7\%; i.e., 44/48).

\section{Safety vs. Efficiency}

Figure 3 shows a trend in research reporting on swallowing safety and swallowing efficiency. Although a rising trend is seen across both themes over time, a significant discrepancy exists between the proportion of articles reporting Post-Swallow Residue (29.9\%) compared to those reporting Aspiration/Penetration (73.2\%) (Pearson $\chi^{2}=6.961$, $\mathrm{p}=0.008)$.

\section{Management Options}

Over 100 unique keywords were identified related to dysphagia management in MND, across $117 / 157$ articles. When grouped thematically, the most commonly discussed management recommendation was Enteral Nutrition, occurring in $63.1 \%$ of all articles (i.e., 99/157). Remaining management themes included: Dietary and Texture Modification (40.8\%), Rehabilitation/Compensatory Strategies (37.6\%), treatment options for Cricopharyngeal Dysfunction (14.0\%), treatment to aid Secretion Management (10.8\%), Surgical Treatment (excluding cricopharyngeal myotomy) (8.9\%), and "Other"options which did not group within a common theme (e.g., pharmaceutical, prosthetic) (7.6\%). Across decades, steady rising trends are seen for Enteral Nutrition, Dietary and Texture Modification, and Rehabilitation/Compensatory Strategies, while Surgical Treatment and treatments for Cricopharyngeal Dysfunction or Secretion Management have remained relatively stable (i.e., $<10$ articles per decade, shown in Figure 4). Notably, $48.7 \%$ of recommendations (i.e., 57/117) were based on secondary source review (i.e., coded [R]), and $47.0 \%$ of recommendations (i.e., 55/117) were based on clinical observation or patient report (i.e., coded [CF]). Only 5 articles reported using instrumental assessment to evaluate a recommended treatment approach (i.e., coded [IF]).

\section{DISCUSSION}

The aim of this scoping review was to summarize the existing research literature in terms of how dysphagia in MND is described, and how it has been studied to date. Our results point to various strengths and limitations in the existing knowledge base, which can be used to guide future research and provide suggestions to clinicians working with individuals with MND.

\section{Question 1: How does the existing research describe swallowing physiology and dysphagia in MND?}

Although there are common physiological characteristics, the individual presentation and clinical impact of dysphagia in MND is highly variable. It is encouraging that the 
description of dysphagia across existing research is comparably variable, and reaches beyond the physiological changes seen in swallowing. While we identified many common themes that describe dysphagia in MND in terms of its clinical presentation (e.g., Aspiration/Penetration, Oral Phase Difficulties, Pharyngeal Phase Difficulties), we also identified descriptors related to the physiological changes contributing to swallowing impairment (e.g., Changes in Muscle Tone), and personal/health-related Consequences of Dysphagia (e.g., reduced quality of life, chest infections, malnutrition). The relationships between swallowing function, disease severity, and secondary health consequences are important to consider when gaining the full clinical picture of ALS and related MNDs. In addition to the physiological health risks associated with dysphagia, swallowing impairments in individuals with ALS are also associated with fatigue and prolonged eating duration, contributing to overall reduced swallow-related quality of life [26]. Figure 5 is a schematic illustration of several possible relationships between swallowing function and related themes, which are extrinsically related to swallowing physiology and function. As we were unable to explore these relationships in detail within the context of this scoping review, future research and systematic review exploring the various relationships between swallowing function and each extrinsic theme these themes will be of great value.

As aforementioned, the research articles included in our thematic analysis include reports on all four MND subtypes, with ALS representing much of our data. When we explored the research reporting themes for classic ALS independently from non-ALS subtypes of MND, or unspecified/aggregated MND data, the descriptive themes did not change significantly. Still, it is important to note that the subtypes are known to differ in terms of disease progression, prognosis and overall impact on functional independence. Further, the clinical presentation and progression of swallowing impairment and dysphagia in MND is heterogeneous - even between subtypes classic ALS, grouped by onset-type (i.e., bulbar- vs. spinal-onset). Several factors reported to influence or predict the severity and rate of progression of dysphagia in MND (particularly ALS), include: age at disease onset (i.e., older individuals often progress faster, require non-oral feeding sooner) [27-29], sex (i.e., females often present with bulbar symptoms earlier, and possibly greater severity) [27,30,31], and symptom onset (i.e., bulbar-onset ALS and PBP show faster rate of decline, different clinical presentation) $[13,15,30,32,29]$. Disease duration and the length of time since onset of bulbar symptoms have also been reported as prognostic indicators of function and severity $[29,33]$.

With respect to non-ALS subtypes of MND, few studies reported only on PBP ( $n=4)$ or PLS $(\mathrm{n}=2)$, and no studies reported only on swallowing in PMA. To that end, we do not have enough information to provide comprehensive presentations of dysphagia and swallowing physiology, by MND subtype. Still, some common features of dysphagia have been noted for specific subtypes; individuals with PBP ( $\mathrm{n}=5$ studies) are reported to have issues with chewing and oral bolus preparation, attributed to orofacial weakness, and may require multiple swallows to clear a single bolus. Further, individuals with PBP may present with a weak cough, bowing of the vocal folds, orofacial pain or changes in sensation, as well as oropharyngeal retention and prolonged esophageal transit [34-37]. Common features that have been noted for individuals with PLS ( $\mathrm{n}=3$ studies) include: choking, impaired tongue movements, nasal regurgitation, and increased esophageal transit time [19,38]. 
A recent report by Szacka and colleagues (2016) is the only study we identified which reported independent results for each MND subtype. In this study, results from scintigraphy showed that patients with classic ALS and PBP demonstrated oropharyngeal retention and prolonged esophageal transit, while individuals with PLS and PMA presented only with prolonged esophageal transit [17]. Upon further exploration of UMN versus LMN involvement in the participant sample, the authors were able to infer that LMN damage appeared to have the greatest influence on esophageal transit. Future studies may consider characterizing participant samples in a similar manner, by reporting by subtype and providing estimates of UMN/LMN and spinal/bulbar involvement to explore additional variables related to swallowing function in MND.

\section{Question 2: How is swallowing physiology and function in individuals with MND being measured and reported?}

Instrumental assessments provide the most comprehensive evaluation of swallowing physiology through visualization of the swallowing sequence, and/or measurement of swallowing function. Although $91.8 \%$ of studies describing Pharyngeal Phase Difficulties based their data on instrumental assessment, reports of Oral Phase Difficulties and Aspiration/Penetration were more likely to be based on clinical signs and patient-reported symptoms; instrumental assessments were cited as the source of these observations $65.5 \%$ and $62.1 \%$ of the time, respectively. As recent findings have identified that aspiration may be silent in individuals with MND (e.g., [16,39-41]), this challenges the sensitivity and specificity of clinical observation and patient report, and highlights the importance of conducting instrumental assessment of swallowing with these individuals. In the clinical context, considerations regarding patient goals and priorities, rate of disease progression, and risks associated with repeat radiation exposure (i.e., videofluoroscopy) will help guide the use of instrumental assessment.

Instrumental assessment of swallowing has provided insight regarding the pathophysiology of swallowing in MNDs. Observations from radiographic imaging and endoscopy include delayed swallow onset $[15,39,41-44]$, the occurrence of penetration/aspiration $[13,15,16,18,27,33,39,41-62]$ and post-swallow residue $[15,16,33,39,41,42,44,47,49,52,53,57-63]$. Additional reports from VFSS indicate reduced hyolaryngeal movement $[15,33,43,45,53,64]$ and incomplete laryngeal closure [45,39]. Still, the majority of studies reporting swallowing physiology/function present observations in descriptive terms, limiting our ability to compare results across studies or measure discrete degrees of change. For example, hyolaryngeal excursion is often reported as "reduced" (e.g., $[33,45,60])$, however, when measured in reference to a scalar or anatomical marker, the results are more variable (e.g., $[51,65])$. Quantification of swallowing physiology has largely been limited to studies using manometry (e.g., $[40,59,66])$ and EMG (e.g., [67,68]).

Manometry studies have yielded measures of reduced pharyngeal pressure during swallowing, and variable cricopharyngeal tonicity [16,41,45,40,69-71]. Recordings taken from EMG have identified longer swallow durations [67,68,72], variability in cricopharyngeal pause duration [68,72], and discoordination between the timing of laryngeal excursion and cricopharyngeal relaxation [72]. Additional tools used as part of a swallowing assessment, including spirometry/airflow measures, tongue pressure measurement, and 
sonography, have identified (respectively): irregularities in voluntary cough airflow and respiratory-swallow coordination [67,73-75], reduced swallow pressures and maximum isometric tongue strength [52,76-78], and reduced tongue thickness and reduced/ disorganized tongue movement during swallowing [29,78,79]. Taken together, research todate has generated a great deal of information regarding the physiological and functional differences of swallowing that may be observed in individuals with MND. An appropriate next-step is to identify relationships between swallowing physiology and function; knowledge regarding these relationships remains limited as few studies have sought to isolate the key physiological mechanisms contributing to functional impairment.

Associations have been identified between reduced tongue thickness, tongue strength, and the presence of oral residue; further, predictive associations have been identified between measures of voluntary cough airflow and risk of aspiration [74]. Reasonable relationships have also been postulated between pharyngeal pressure and the accumulation of postswallow residue (e.g., [40]), as well as premature spill of liquids or hyolaryngeal elevation and risk of penetration/aspiration (e.g., [39]); however, direct correlations and associated estimates of relative risk have yet to be established. Further exploration of the key physiological mechanisms contributing to functional swallowing impairments will provide outcome measures for clinical trials, serve as markers to identify relative risk of functional impairment, and provide proof of principle for targeted swallowing management options.

Impairments in swallowing safety and efficiency have been recognized in individuals with MND since the 1960s; in fact, three of the four earliest articles included in this review reported radiologically-confirmed impairments in both swallowing safety and efficiency $[49,58,63]$. However, over time, research has placed a greater emphasis on swallowing safety than swallowing efficiency: almost three-quarters (73.6\%) of research articles identify Aspiration/Penetration as a concern in individuals with MND, while just under a third (30.2\%) discuss Post-Swallow Residue; (27.7\% discuss both). We hypothesize that this discrepancy is stable across the field of dysphagia, due to known risks associated with aspiration, including aspiration pneumonia. Still, this finding highlights an imbalance in research focus that has the potential to minimize the occurrence and clinical importance of post-swallow residue. In non-MND populations, post-swallow residue has been linked with malnutrition [80-82], which poses an inevitable concern faced by individuals with ALS and related MNDs. Further, some reports from instrumental assessment show that the occurrence of post-swallow residue is more frequent than aspiration $[44,52,58-60,62]$ in patients with ALS, and may even present an independent risk factor for later aspiration events $[39,40,66]$. In a recent study by Fattori and colleagues (2016), post-swallow residue was found to be significantly associated with clinical stage of ALS, measured by the Amyotrophic Lateral Sclerosis Functioning Rating Scale (ALSFRS-R) [84], regardless of onset-type. Taken together, these reports suggest that more research is needed to investigate the factors which lead to the accumulation of post-swallow residue, and the impact it has on individuals with ALS and related MNDs.

\section{Question 3: What recommendations are being made for dysphagia management?}

Across the literature, the most common recommendation for dysphagia management in patients with MND is enteral nutrition. As MNDs are progressive with no known cure, 
enteral nutrition is a key management option to reduce the risk of secondary consequences resulting from dysphagia, and maintain optimal health status. Enteral nutrition has been shown improve or maintain to nutritional status [85], weight gain [86-88], and prolonged survival $[89,90]$ provided that respiratory status is adequate [91,92]. Current recommendations indicate that prophylactic introduction of an enteral nutrition method (e.g., PEG-tube) is preferred, in order to supplement nutrition early and ensure that respiratory capacity is adequate (e.g., FVC $>50 \%$ ) at the time of surgery [93,94]. Still, enteral feeding does not directly treat the disordered swallow, but rather provides nutritional supplementation in the absence of a safe or efficient swallow. Research on direct management strategies to improve or mitigate swallowing function has been much more limited.

With respect to direct swallowing strategies, a number of techniques have been suggested, including (but not limited to): compensatory maneuvers (e.g., supra-glottic swallow, Mendelsohn maneuver, chin tuck, head turn, head flexion) [11,12,14,39,45,49,61,66,79,95105]; behavioural strategies (e.g., reduced bolus size, taking multiple swallows, avoiding distractions during meals) [12,14,42,57,61,97,100-102,104-106]; sensory tricks (e.g., vibration, thermal stimulation, increase sensory aspects of bolus) [14,57,97,100,102,105,107]; and dietary modifications (e.g., mechanically altered food, thickened liquids, soft diet, liquidize food) [11-14,29,39,42,49,54,57,61,66,79,95-116]. Still, almost half (48\%) of these recommendations were provided as secondary source review (e.g., $[12,14,100,102,104,105])$, which may include general techniques that have not been specifically evaluated for individuals with MND. Of the studies presenting original research findings to support their recommendations, many studies did not describe their efficacy $[30,42,57,117,112,101]$, or concluded that swallowing function improved based solely on patient report [118]. Only four studies used instrumental assessment to confirm the effectiveness of a prescribed diet texture modification or compensatory strategy to prevent aspiration [39,45,56,61]. Watts \& Vanryckeghem (2001) reported that chin-tuck posture and thickened liquids were effective strategies to prevent aspiration in a single case example. Rubin et al. (2013) presented a case report of a woman with ALS and reported that taking small sips was effective to stop aspiration; however, a head turn was ineffective. Lo Re et al. (2007) evaluated the efficacy of head position (i.e., extension vs. flexion) in a group of ALS patients and reported benefit of anterior head flexion to reduce aspiration/penetration during the swallow. In the most comprehensive study to date, Solazzo et al. (2011) used VFSS used to evaluate the effectiveness of three compensatory postures: chin-tuck, head rotation, and hyperextended head $(n=81)$. Their results suggested that each strategy was effective at eliminating aspiration in very specific contexts; however, not all strategies were effective with all participants. To that end, the authors advise the use of instrumental assessment to identify appropriate management strategies for individuals with MND.

Recently, more active interventions aimed at improving/maintaining swallowing function in individuals with ALS have been explored, particularly aimed at targeting early stages of the disease. Although active rehabilitation has historically been cautioned for individuals with ALS and related MNDs (e.g., [101,119]), a review by Plowman (2015) concluded that mild forms of exercise may have a positive effect on maintaining motor function in patients with ALS; still, it was advised that more research would be needed to fully understand the role of 
exercise and its influence on bulbar function. In a recent study by Plowman and colleagues (2016), expiratory muscle strength training led to measurable improvements in maximum expiratory pressure and hyoid displacement, in patients with ALS; however, clinically significant changes in penetration-aspiration severity or measures of voluntary cough were not observed. Tongue strengthening has also been piloted as a potential rehabilitative option, which showed increases in tongue strength and endurance in both included participants $(n=2)$, compared to lead in baseline measures; however, no improvements were seen with respect to swallowing safety [121]. Although in preliminary stages, this evolving research is hopeful to expand our understanding of ALS and related MNDs, and identify potential therapeutic targets to maintain swallowing function, for as long as possible.

\section{Unexpected findings}

MNDs have classically been considered to selectively impair motor neurons. This has provided a rationale for using sensory tricks in dysphagia management - on the assumption that these strategies exploit unimpaired mechanisms to compensate for impaired motor function (e.g., [30,101]). However, we were surprised to find that 7 articles (i.e., $4.5 \%$ of all reviewed articles) reported observing silent aspiration [13,16,39,41,45,62,122], and an additional subset of articles reported sensory changes such as reduced laryngeal sensitivity, changes in taste, and odynophagia $[32,37,46,112,123]$. These observations support a more contemporary view of MND as a multi-system disorder [124]. As sensory impairment at the level of the larynx has been shown to place stroke patients at greater risk of aspirating thin liquids, irrespective of motor function $[125,126]$, the confirmed presence of sensory dysfunction in MND would have important implications for our understanding of the underlying pathophysiology of dysphagia in this population.

\section{Limitations}

Several limitations must be taken into account when interpreting our findings. First, only English articles were included in this dataset, excluding research in other languages. Further, the purpose of this study was to gain insight into the profile of existing research on swallowing function in MND, by tabulating the frequency of reported themes. Given this objective, the quality of experimental studies in our database quality was not specifically appraised. Systematic reviews including quality appraisal of research describing swallowing pathophysiology and treatment outcomes will be needed in the future to support conclusions regarding dysphagia and its management in MND.

For the purpose of this review, we opted to include all four MND subtypes, rather than focusing specifically on classic ALS, in order to be inclusive and avoid biasing the data based on regional differences in labelling and reporting of MNDs. Still, this creates a limitation due to known differences in clinical presentation and prognosis between the subtypes. When we explored the proportion of themes between clearly defined classic ALS, against mixed reports (i.e., aggregate MND data) or ambiguous/unspecified MND-type, the results remained stable. Still, the variability between subtypes, as well as variability between cases of bulbar- and spinal-onset ALS, could not be captured in this review. In future research, it may be beneficial to extend beyond a classification of subtype/onset-type, and include estimates of the degree to which bulbar/spinal pathways and UMN/LMNs are 
affected within the participant sample; this level of detail would allow us to delineate how swallowing physiology and related issues are affected by the idiosyncrasies of each subtype, and between bulbar- and spinal-onsets of ALS.

We also acknowledge that while we aimed to keep this review relatively broad in order to capture overall themes and trends of existing research, we kept a narrow-focus on swallowing physiology and function in our definition of "dysphagia." It is important to note that there are many related areas of study that significantly interact with swallowing, such as nutrition and respiratory status, that were not explored in exhaustive detail. This constraint has the potential to present a limited perspective on the overall clinical management of ALS and related MNDs, for which a multi-disciplinary approach has been well-supported (e.g., $[113,127])$. More specifically, the occurrence and management recommendations targeting aspiration pneumonia were not extracted in our literature search, omitting a discussion regarding functional airway clearance, and the roles of assisted-cough strategies, manual insufflation/exsufflation, and non-invasive positive pressure ventilation (for examples, see Sancho et al. (2004; 2007); Miller et al. (2009); Britton et al. (2014)). These closely-related areas of study reach beyond the scope of this review, highlighting the need for future study and systematic review of these very important clinical issues.

\section{Clinical \& Research Implications}

Our findings highlight the breadth and variability of studies describing dysphagia in MNDs, capturing the complexity of the problem, while identifying existing imbalances in research focus. Such imbalances are important to consider, as they may leave researchers and clinicians with disproportionate concerns and create the potential to overlook important details. Given the breadth found in research descriptions of dysphagia in MND, it is important that clinicians and researchers working with this population approach patients without assumptions and conduct comprehensive oral motor and swallowing examinations to determine how the individual is affected and identify mechanisms contributing to swallowing impairment. To that end, it is equally important that management practices are chosen to target specific observed impairments, and that efficacy is tested using instrumental evaluation. Future research should continue to investigate the pathophysiology of impairments in swallowing safety and efficiency in MND, in addition to considering the factors that influence secondary consequences including changes in participation and quality of life.

\section{Supplementary Material}

Refer to Web version on PubMed Central for supplementary material.

\section{Acknowledgments}

Acknowledgements and funding: The authors wish to thank Jessica Babineau, MLIS from the Toronto Rehabilitation Institute - University Health Network, for her work in defining and translating the initial search strategy. We also extend appreciation to Professor Heather Colquhoun from the University of Toronto, Rehabilitation Sciences Institute for her guidance with scoping review methodology. This work was supported in part by doctoral research funding provided by the University of Toronto, Rehabilitation Sciences Institute. 


\section{References}

1. National Institute of Neurological Disorders and Stroke. [Accessed 25 September 2016] Motor Neuron Diseases Fact Sheet. 2012. http://www.ninds.nih.gov/disorders/motor_neuron_diseases/ detail_motor_neuron_diseases.htm

2. World Health Organization. [Accessed 14 November 2015] International Statistical Classification of Diseases and Related Health Problems (10th Revision). 2015. http://apps.who.int/classifications/ icd10/browse/2016/en

3. Karam C, Scelsa SN, MacGowan DJL. The clinical course of progressive bulbar palsy. Amyotroph. 2010; 11(4):364-368. DOI: 10.3109/17482960903513159

4. Gordon PH, Cheng B, Katz IB, Pinto M, Hays AP, Mitsumoto H, Rowland LP. The natural history of primary lateral sclerosis. Neurology. 2006; 66(5):647-653. [PubMed: 16534101]

5. Al-Chalabi A, Hardiman O, Kiernan MC, Chiò A, Rix-Brooks B, van den Berg LH. Amyotrophic lateral sclerosis: moving towards a new classification system. The Lancet Neurology. 2016; 15(11): 1182-1194. [PubMed: 27647646]

6. Swinnen B, Robberecht W. The phenotypic variability of amyotrophic lateral sclerosis. Nature reviews Neurology. 2014; 10(11):661. [PubMed: 25311585]

7. Miller, RM., Britton, D. Dysphagia in neuromuscular diseases. Plural Publishing; 2011.

8. D’Amico E, Pasmantier M, Lee Y-W, Weimer L, Mitsumoto H. Clinical Evolution of Pure Upper Motor Neuron Disease/Dysfunction (PUMND). Muscle \& Nerve. 2013; 47(1):28-32. DOI: 10.1002/mus.23496 [PubMed: 23169452]

9. Valadi N. Evaluation and management of amyotrophic lateral sclerosis. Prim Care. 2015; 42(2):177187. doi:http://dx.doi.org/10.1016/j.pop.2015.01.009. [PubMed: 25979579]

10. Barber C. Management of bulbar symptoms in motor neurone disease: a community speech and language therapist perspective. British Journal of Neuroscience Nursing. 2015; 11(1):41-46. 46p.

11. Borasio GD, Miller RG. Clinical characteristics and management of ALS. Semin Neurol. 2001; 21(2):155-166. [PubMed: 11442324]

12. Houseman G. Symptom management of the patient with amyotrophic lateral sclerosis: a guide for hospice nurses. Journal of Hospice \& Palliative Nursing. 2008; 10(4):207-215. 209p.

13. Ruoppolo G, Schettino I, Frasca V, Giacomelli E, Prosperini L, Cambieri C, Roma R, Greco A, Mancini P, De Vincentiis M, Silani V, Inghilleri M. Dysphagia in amyotrophic lateral sclerosis: prevalence and clinical findings. Acta Neurol Scand. 2013; 128(6):397-401. doi:http://dx.doi.org/ 10.1111/ane.12136. [PubMed: 23668293]

14. Kuhnlein P, Gdynia HJ, Sperfeld AD, Lindner-Pfleghar B, Ludolph AC, Prosiegel M, Riecker A. Diagnosis and treatment of bulbar symptoms in amyotrophic lateral sclerosis. Nat Clin Pract Neurol. 2008; 4(7):366-374. doi:http://dx.doi.org/10.1038/ncpneuro0853. [PubMed: 18560390]

15. Robbins J. Swallowing in ALS and motor neuron disorders. Neurol Clin. 1987; 5(2):213-229. [PubMed: 11681400]

16. Briani C, Marcon M, Ermani M, Costantini M, Bottin R, Iurilli V, Zaninotto G, Primon D, Feltrin G, Angelini C. Radiological evidence of subclinical dysphagia in motor neuron disease. J Neurol. 1998; 245(4):211-216. [PubMed: 9591222]

17. Szacka KP-C, Fronczewska-Wieniawska A, Spychaa K, Krolicki A, Kuma-Kozakiewicz LM. Scintigraphic evaluation of mild to moderate dysphagia in motor neuron disease. Clinical Nuclear Medicine. 2016; 41(4):e175-e180. doi:http://dx.doi.org/10.1097/RLU.0000000000001162. [PubMed: 26914558]

18. Leighton SE, Burton MJ, Lund WS, Cochrane GM. Swallowing in motor neurone disease. J R Soc Med. 1994; 87(12):801-805. [PubMed: 7853320]

19. Watanabe R, Iino M, Honda M, Sano J, Hara M. Primary lateral sclerosis. Neuropathology. 1997; 17(3):220-224.

20. Corcia P, Pradat PF, Salachas F, Bruneteau G, le Forestier N, Seilhean D, Hauw JJ, Meininger V. Causes of death in a post-mortem series of ALS patients. Amyotroph. 2008; 9(1):59-62. DOI: $10.1080 / 17482960701656940$ 
21. Levac D, Colquhoun H, O'Brien KK. Scoping studies: advancing the methodology. Implementation Science. 2010; 5(1):69.doi: 10.1186/1748-5908-5-69 [PubMed: 20854677]

22. Pham MT, Rajić A, Greig JD, Sargeant JM, Papadopoulos A, McEwen SA. A scoping review of scoping reviews: advancing the approach and enhancing the consistency. Research Synthesis Methods. 2014; 5(4):371-385. [PubMed: 26052958]

23. Colquhoun HL, Levac D, O’Brien KK, Straus S, Tricco AC, Perrier L, Kastner M, Moher D. Scoping reviews: time for clarity in definition, methods, and reporting. Journal of clinical epidemiology. 2014; 67(12):1291-1294. [PubMed: 25034198]

24. Arksey H, O’Malley L. Scoping studies: towards a methodological framework. International Journal of Social Research Methodology. 2005; 8(1):19-32. DOI: 10.1080/1364557032000119616

25. Viera AJ, Garrett JM. Understanding interobserver agreement: the kappa statistic. Family medicine. 2005; 37(5):360. [PubMed: 15883903]

26. Tabor LG, Watts J, Robison S, Plowman R, EK. Defining Swallowing-Related Quality of Life Profiles in Individuals with Amyotrophic Lateral Sclerosis. Dysphagia. 2016; 31(3):376-382. doi:http://dx.doi.org/10.1007/s00455-015-9686-2. [PubMed: 26837611]

27. Luchesi KF, Kitamua S, Mourao LF. Amyotrophic Lateral Sclerosis survival analysis: Swallowing and non-oral feeding. NeuroRehabilitation. 2014; 35(3):535-542. doi:http://dx.doi.org/10.3233/ NRE-141149. [PubMed: 25238863]

28. Atsuta N, Watanabe H, Ito M, Tanaka F, Tamakoshi A, Nakano I, Aoki M, Tsuji S, Yuasa T, Takano H, Hayashi H, Kuzuhara S, Sobue G. Research Committee on the Neurodegenerative Diseases of J. Age at onset influences on wide-ranged clinical features of sporadic amyotrophic lateral sclerosis. J Neurol Sci. 2009; 276(1-2):163-169. doi:http://dx.doi.org/10.1016/j.jns. 2008.09.024. [PubMed: 18962725]

29. Nakamori MH, Takaki N, Oda S, Hiraoka M, Yoshikawa A, Matsushima M, Ochi H, Tsuga K, Maruyama K, Izumi H, Matsumoto YM. Tongue thickness evaluation using ultrasonography can predict swallowing function in amyotrophic lateral sclerosis patients. Clin Neurophysiol. 2016; 127(2):1669-1674. [PubMed: 26323377]

30. Strand EA, Miller RM, Yorkston KM, Hillel AD. Management of oral-pharyngeal dysphagia symptoms in amyotrophic lateral sclerosis. Dysphagia. 1996; 11(2):129-139. [PubMed: 8721072]

31. Lever TE, Simon E, Cox KT, Capra NF, O'Brien KF, Hough MS, Murashov AK. A mouse model of pharyngeal dysphagia in amyotrophic lateral sclerosis. Dysphagia. 2010; 25(2):112-126. doi:http://dx.doi.org/10.1007/s00455-009-9232-1. [PubMed: 19495873]

32. Luchesi KF, Kitamura S, Mourao LF. Higher risk of complications in odynophagia-associated dysphagia in amyotrophic lateral sclerosis. Arq Neuropsiquiatr. 2014; 72(3):203-207. [PubMed: 24676437]

33. Higo R, Tayama N, Nito T. Longitudinal analysis of progression of dysphagia in amyotrophic lateral sclerosis. Auris Nasus Larynx. 2004; 31(3):247-254. [PubMed: 15364359]

34. Baker L. Motor neurone disease: overview and case study -- a community nursing perspective. Australasian Journal of Neuroscience. 1997; 10(2):6-9. 4p.

35. Cerero Lapiedra R, Moreno Lopez LA, Esparza Gomez GC. Progressive bulbar palsy: a case report diagnosed by lingual symptoms. J Oral Pathol Med. 2002; 31(5):277-279. [PubMed: 12110044]

36. Smith RO, Sands CJ, Goldberg NM, Massey RU, Gay JR. Injection of silicone lateral to a vocal cord in a patient with progressive bulbar palsy. Neurology. 1967; 17(12):1217-1218. [PubMed: 6070024]

37. Talacko AA, Reade PC. Progressive bulbar palsy: a case report of a type of motor neuron disease presenting with oral symptoms. Oral Surg Oral Med Oral Pathol. 1990; 69(2):182-184. [PubMed: 2304745]

38. Beal MF, Richardson EP Jr. Primary lateral sclerosis: a case report. Arch Neurol. 1981; 38(10): 630-633. [PubMed: 7295106]

39. Lo Re G, Galia M, La Grutta L, Russo S, Runza G, Taibbi A, D’Agostino T, Lo Greco V, Bartolotta TV, Midiri M, Cardinale AE, De Maria M, Lagalla R. Digital cineradiographic study of swallowing in patients with amyotrophic lateral sclerosis. Radiol Med (Torino). 2007; 112(8): 1173-1187. [PubMed: 18080096] 
40. Goeleven A, Robberecht W, Sonies B, Carbonez A, Dejaeger E. Manofluorographic evaluation of swallowing in amyotrophic lateral sclerosis and its relationship with clinical evaluation of swallowing. Amyotroph Lateral Scler. 2006; 7(4):235-240. [PubMed: 17127562]

41. Noh EJ, Park MI, Park SJ, Moon W, Jung HJ. A case of amyotrophic lateral sclerosis presented as oropharyngeal Dysphagia. J Neurogastroenterol Motil. 2010; 16(3):319-322. doi:http://dx.doi.org/ 10.5056/jnm.2010.16.3.319. [PubMed: 20680172]

42. Leder SB, Novella S, Patwa H. Use of fiberoptic endoscopic evaluation of swallowing (FEES) in patients with amyotrophic lateral sclerosis. Dysphagia. 2004; 19(3):177-181. [PubMed: 15383947]

43. Li S, Chen Q, Yu B, Xue K, Luo C, Xu Y, Gong Q, He C, Zhou D, He L, Yao D. Structural and functional changes mapped in the brains of amyotrophic lateral sclerosis patients with/without dysphagia: a pilot study. Amyotroph. 2009; 10(5-6):280-287. doi:http://dx.doi.org/ 10.3109/17482960902893342.

44. Paris G, Martinaud O, Petit A, Cuvelier A, Hannequin D, Roppeneck P, Verin E. Oropharyngeal dysphagia in amyotrophic lateral sclerosis alters quality of life. J Oral Rehabil. 2013; 40(3):199_ 204. doi:http://dx.doi.org/10.1111/joor.12019. [PubMed: 23278936]

45. Solazzo A, Del Vecchio L, Reginelli A, Monaco L, Sagnelli A, Monsorro M, Di Martino N, Tedeschi G, Grassi R. Search for compensation postures with videofluoromanometric investigation in dysphagic patients affected by amyotrophic lateral sclerosis. Radiol Med (Torino). 2011; 116(7):1083-1094. doi:http://dx.doi.org/10.1007/s11547-011-0698-1. [PubMed: 21643631]

46. Amin MR, Harris D, Cassel SG, Grimes E, Heiman-Patterson T. Sensory testing in the assessment of laryngeal sensation in patients with amyotrophic lateral sclerosis. Ann Otol Rhinol Laryngol. 2006; 115(7):528-534. [PubMed: 16900807]

47. D’Ottaviano FG, Linhares Filho TA, Andrade HM, Alves PC, Rocha MS. Fiberoptic endoscopy evaluation of swallowing in patients with amyotrophic lateral sclerosis. Rev Bras Otorrinolaringol (Engl Ed). 2013; 79(3):349-353. doi:http://dx.doi.org/10.5935/1808-8694.20130061.

48. Bevan K, Griffiths MV. Chronic aspiration and laryngeal competence. Journal of Laryngology and Otology. 1989; 103(2):196-199. [PubMed: 2926269]

49. Bosma JF, Brodie DR. Disabilities of the pharynx in amyotrophic lateral sclerosis as demonstrated by cineradiography. Radiology. 1969; 92(1):97-103. [PubMed: 5762099]

50. Fattori B, Grosso M, Bongioanni P, Nacci A, Cristofani R, AlSharif A, Licitra R, Matteucci F, Rossi B, Rubello D, Ursino F, Mariani G. Assessment of swallowing by oropharyngoesophageal scintigraphy in patients with amyotrophic lateral sclerosis. Dysphagia. 2006; 21(4):280-286. [PubMed: 17221290]

51. Kawai S, Tsukuda M, Mochimatsu I, Enomoto H, Kagesato Y, Hirose H, Kuroiwa Y, Suzuki Y. A study of the early stage of Dysphagia in amyotrophic lateral sclerosis. Dysphagia. 2003; 18(1):1-8. [PubMed: 12497190]

52. Morimoto N, Yamashita T, Sato K, Kurata T, Ikeda Y, Kusuhara T, Murata N, Abe K. Assessment of swallowing in motor neuron disease and Asidan/SCA36 patients with new methods. J Neurol Sci. 2013; 324(1-2):149-155. doi:http://dx.doi.org/10.1016/j.jns.2012.10.025. [PubMed: 23146615]

53. Murono S, Hamaguchi T, Yoshida H, Nakanishi Y, Tsuji A, Endo K, Kondo S, Wakisaka N, Yamada M, Yoshizaki T. Evaluation of dysphagia at the initial diagnosis of amyotrophic lateral sclerosis. Auris Nasus Larynx. 2015; 42(3):213-217. doi:http://dx.doi.org/10.1016/j.anl. 2014.10.012. [PubMed: 25466359]

54. Nozaki S, Sugishita S, Saito T, Umaki Y, Adachi K, Shinno S. Prolonged apnea/hypopnea during water swallowing in patients with amyotrophic lateral sclerosis. Rinsho Shinkeigaku. 2008; 48(9): 634-639. [PubMed: 19048945]

55. Restivo DA, Casabona A, Nicotra A, Zappia M, Elia M, Romano MC, Alfonsi E, MarcheseRagona R. ALS dysphagia pathophysiology: differential botulinum toxin response. Neurology. 2013; 80(7):616-620. doi:http://dx.doi.org/10.1212/WNL.0b013e318281cc1b. [PubMed: 23345638] 
56. Rubin AD, Griffin GR, Hogikyan ND, Feldman EL. A new member of the multidisciplinary ALS team: the otolaryngologist. Amyotroph. 2012; 13(2):229-232. doi:http://dx.doi.org/ 10.3109/17482968.2011.643898.

57. Scott A, Heughan A. A review of dysphagia in four cases of motor neurone disease. Palliat Med. 1993; 7(4 Suppl):41-47. [PubMed: 7505710]

58. Silverstein A, Faegenburg D. Cineradiography of Swallowing. Observation in Patients with Lesions of Brain Stem, Lower Cranial Nerves, or Bulbar Musculature. Arch Neurol. 1965; 12:6771. [PubMed: 14224861]

59. Takasaki K, Umeki H, Enatsu K, Kumagami H, Takahashi H. Evaluation of swallowing pressure in a patient with amyotrophic lateral sclerosis before and after cricopharyngeal myotomy using highresolution manometry system. Auris Nasus Larynx. 2010; 37(5):644-647. doi:http://dx.doi.org/ 10.1016/j.anl.2010.02.003. [PubMed: 20172669]

60. Teismann IK, Warnecke T, Suntrup S, Steinstrater O, Kronenberg L, Ringelstein EB, Dengler R, Petri S, Pantev C, Dziewas R. Cortical processing of swallowing in ALS patients with progressive dysphagia--a magnetoencephalographic study. PLoS ONE. 2011; 6(5):e19987. doi:http:// dx.doi.org/10.1371/journal.pone.0019987. [PubMed: 21625445]

61. Watts CR, Vanryckeghem M. Laryngeal dysfunction in Amyotrophic Lateral Sclerosis: A review and case report. BMC Ear, Nose and Throat Disorders. 2001; 1:1-5. doi:http://dx.doi.org/ 10.1186/1472-6815-1-1.

62. Wright R, Jordan C. Videofluoroscopic evaluation of dysphagia in motor neurone disease with modified barium swallow. Palliat Med. 1997; 11(1):44-48. [PubMed: 9068684]

63. Kiuchi S, Sasaki J, Arai T, Suzuki T. Functional disorders of the pharynx and esophagus. Acta Otolaryngol Suppl (Stockh). 1969; 256:1-30. [PubMed: 4986613]

64. Wada A, Kawakami M, Liu M, Otaka E, Nishimura A, Liu F, Otsuka T. Development of a new scale for dysphagia in patients with progressive neuromuscular diseases: the Neuromuscular Disease Swallowing Status Scale (NdSSS). J Neurol. 2015; 262(10):2225-2231. doi:http:// dx.doi.org/10.1007/s00415-015-7836-y. [PubMed: 26142025]

65. Plowman EK, Watts SA, Tabor L, Robison R, Gaziano J, Domer AS, Richter J, Vu T, Gooch C. Impact of expiratory strength training in amyotrophic lateral sclerosis. Muscle Nerve. 2016; 54(1): 48-53. DOI: 10.1002/mus.24990 [PubMed: 26599236]

66. Solazzo A, Monaco L, Vecchio LD, Reginelli A, Iacobellis F, Capasso R, Tamburrini S, Berritto D, Barillari MR, Monsurro MR, Di Martino N, Grassi R. Earliest videofluoromanometric pharyngeal signs of dysphagia in ALS patients. Dysphagia. 2014; 29(5):539-544. doi:http://dx.doi.org/ 10.1007/s00455-014-9542-9. [PubMed: 25142240]

67. Aydogdu I, Tanriverdi Z, Ertekin C. Dysfunction of bulbar central pattern generator in ALS patients with dysphagia during sequential deglutition. Clin Neurophysiol. 2011; 122(6):12191228. doi:http://dx.doi.org/10.1016/j.clinph.2010.11.002. [PubMed: 21111672]

68. Ertekin C, Aydogdu I, Yuceyar N, Kiylioglu N, Tarlaci S, Uludag B. Pathophysiological mechanisms of oropharyngeal dysphagia in amyotrophic lateral sclerosis. Brain. 2000; 123(Pt 1): 125-140. [PubMed: 10611127]

69. Higo R, Tayama N, Watanabe T, Nitou T. Videomanofluorometric study in amyotrophic lateral sclerosis. Laryngoscope. 2002; 112(5):911-917. [PubMed: 12150627]

70. MacDougall G, Wilson JA, Pryde A, Grant R. Analysis of the pharyngoesophageal pressure profile in amyotrophic lateral sclerosis. Otolaryngol Head Neck Surg. 1995; 112(2):258-261. [PubMed: 7838549]

71. Omari TI, Wiklendt L, Dinning P, Costa M, Rommel N, Cock C. Upper esophageal sphincter mechanical states analysis: a novel methodology to describe UES relaxation and opening. Front Syst Neurosci. 2014; 8:241. doi:http://dx.doi.org/10.3389/fnsys.2014.00241. [PubMed: 25610376]

72. Ertekin C, Aydogdu I, Yuceyar N, Tarlaci S, Kiylioglu N, Pehlivan M, Celebi G. Electrodiagnostic methods for neurogenic dysphagia. Electroencephalogr Clin Neurophysiol. 1998; 109(4):331-340. [PubMed: 9751296]

73. Plowman, EKW., Tabor, SA., Robison, L., Gaziano, R., Domer, J., Richter, AS., Vu, J., Gooch, TC. Impact of expiratory strength training in amyotrophic lateral sclerosis. Muscle and Nerve. 2016. doi:http://dx.doi.org/10.1002/mus.24990 
74. Plowman EW, Robison Stephanie, Tabor Raele, Dion Lauren, Gaziano Charles, Vu Joy, Gooch Tuan, Plowman Clifton, Watts Emily K, Stephanie A. Voluntary Cough Airflow Differentiates Safe Versus Unsafe Swallowing in Amyotrophic Lateral Sclerosis. Dysphagia (0179051X). 2016; 31(3):383-390. DOI: 10.1007/s00455-015-9687-1

75. Erdem NSK, Unal K, Kizilay A, Ogus F, Uysal CH. The interaction between breathing and swallowing in amyotrophic lateral sclerosis. Acta Neurologica Belgica. 2016; 116(4):549-556. doi:http://dx.doi.org/10.1007/s13760-016-0643-0. [PubMed: 27151083]

76. Easterling C, Antinoja J, Cashin S, Barkhaus PE. Changes in tongue pressure, pulmonary function, and salivary flow in patients with amyotrophic lateral sclerosis. Dysphagia. 2013; 28(2):217-225. doi:http://dx.doi.org/10.1007/s00455-012-9436-7. [PubMed: 23242462]

77. Kikutani T, Tamura F, Nishiwaki K. Case presentation: dental treatment with PAP for ALS patient. Int J Orofacial Myology. 2006; 32:32-35. [PubMed: 17650766]

78. Umemoto GF, Arahata H, Sugahara H, Sakai M, Tsuboi MY. Relationship between tongue thickness and tongue pressure in neuromuscular disorders. Neurology and Clinical Neuroscience. 2016; 4(4):142-145. doi:http://dx.doi.org/10.1111/ncn3.12058.

79. Tamburrini S, Solazzo A, Sagnelli A, Del Vecchio L, Reginelli A, Monsorro M, Grassi R. Amyotrophic lateral sclerosis: sonographic evaluation of dysphagia. Radiol Med (Torino). 2010; 115(5):784-793. doi:http://dx.doi.org/10.1007/s11547-010-0523-2. [PubMed: 20174881]

80. Carrión S, Cabré M, Monteis R, Roca M, Palomera E, Serra-Prat M, Rofes L, Clavé P. Oropharyngeal dysphagia is a prevalent risk factor for malnutrition in a cohort of older patients admitted with an acute disease to a general hospital. Clinical nutrition. 2015; 34(3):436-442. doi:http://dx.doi.org/10.1016/j.clnu.2014.04.014. [PubMed: 24882372]

81. Rofes L, Arreola V, Almirall J, Cabre M, Campins L, Garcia-Peris P, Speyer R, Clave P. Diagnosis and management of oropharyngeal Dysphagia and its nutritional and respiratory complications in the elderly. Gastroenterology research and practice 2011. 2011; doi: 10.1155/2011/818979

82. Oliveira DL, Moreira EAM, de Freitas MB, de Gonçalves AJ, Furkim AM, Clavé P. Pharyngeal residue and aspiration and the relationship with clinical/nutritional status of patients with oropharyngeal dysphagia submitted to videofluoroscopy. The journal of nutrition, health \& aging. 2017; 21(3):336-341. DOI: 10.1007/s12603-016-0754-6

83. Fattori, BS., Mancini, G., Bastiani, V., Bongioanni, L., Caldarazzo Ienco, P., Barillari, E., Romeo, MR., Nacci, ASO. Dysphagia in Amyotrophic Lateral Sclerosis: Relationships between disease progression and Fiberoptic Endoscopic Evaluation of Swallowing; Auris Nasus Larynx. 2016. p. 17doi:http://dx.doi.org/10.1016/j.anl.2016.07.002

84. Cedarbaum JM, Stambler N, Malta E, Fuller C, Hilt D, Thurmond B, Nakanishi A. The ALSFRSR: a revised ALS functional rating scale that incorporates assessments of respiratory function. Journal of the Neurological Sciences. 1999; 169(1-2):13-21. DOI: 10.1016/ s0022-510x(99)00210-5 [PubMed: 10540002]

85. Chio A, Finocchiaro E, Meineri P, Bottacchi E, Schiffer D. Safety and factors related to survival after percutaneous endoscopic gastrostomy in ALS. ALS Percutaneous Endoscopic Gastrostomy Study Group. Neurology. 1999; 53(5):1123-1125. [PubMed: 10496278]

86. Desport JC, Preux PM, Truong CT, Courat L, Vallat JM, Couratier P. Nutritional assessment and survival in ALS patients. Amyotroph Lateral Scler Other Motor Neuron Disord. 2000; 1(2):91-96. [PubMed: 11467055]

87. Mitsumoto H, Davidson M, Moore D, Gad N, Brandis M, Ringel S, Shefner JM, Strong MJ, Sufit R, Anderson FA, Echols C, Heiman-Patterson T, Paylor T, Huffnagles V, Murphy J, Lou JS, Tullar D, McClusky L, Damiano P, Miller R, Tkachenko I, Neville H, Blackwell KH, Oh S, Olney R, Mass J, Pascuzzi R, Michaels A, Pioro E, Andrews-Hinders D, Rosenfeld J, King R, Scelsa S, Shefner J, Lepsky T, Strong M, Rowe A, Sufit RL, Casey P. Percutaneous endoscopic gastrostomy (PEG) in patients with ALS and bulbar dysfunction. Amyotrophic Lateral Sclerosis and Other Motor Neuron Disorders. 2003; 4(3):177-185. doi:http://dx.doi.org/10.1080/14660820310011728. [PubMed: 13129795]

88. Mazzini L, Corra T, Zaccala M, Mora G, Del Piano M, Galante M. Percutaneous endoscopic gastrostomy and enteral nutrition in amyotrophic lateral sclerosis. J Neurol. 1995; 242(10):695698. [PubMed: 8568533] 
89. Langmore SE, Kasarskis EJ, Manca ML, Olney RK. Enteral tube feeding for amyotrophic lateral sclerosis/motor neuron disease. Cochrane Database Syst Rev. 2006; (4):CD004030. [PubMed: $17054194]$

90. Katzberg, HD., Benatar, M. Enteral tube feeding for amyotrophic lateral sclerosis/motor neuron disease; Cochrane Database Syst Rev. 2011. p. CD004030doi:http://dx.doi.org/ 10.1002/14651858.CD004030.pub3

91. Kasarskis EJ, Scarlata D, Hill R, Fuller C, Stambler N, Cedarbaum JM. A retrospective study of percutaneous endoscopic gastrostomy in ALS patients during the BDNF and CNTF trials. J Neurol Sci. 1999; 169(1-2):118-125. [PubMed: 10540019]

92. Chio A, Galletti R, Finocchiaro C, Righi D, Ruffino MA, Calvo A, Di Vito N, Ghiglione P, Terreni AA, Mutani R. Percutaneous radiological gastrostomy: a safe and effective method of nutritional tube placement in advanced ALS. J Neurol Neurosurg Psychiatry. 2004; 75(4):645-647. [PubMed: 15026518]

93. Benstead TJ-T, Leddin CD. Nutrition with gastrostomy feeding tubes for amyotrophic lateral sclerosis in Canada. Canadian Journal of Neurological Sciences. 2016; 43(6):796-800. doi:http:// dx.doi.org/10.1017/cjn.2016.28. [PubMed: 27039940]

94. Nunes GS, Grunho CA, Fonseca MJ. Enteral feeding through endoscopic gastrostomy in amyotrophic lateral sclerosis patients. Nutr Hosp. 2016; 33(5):561. doi:https://dx.doi.org/ 10.20960/nh.561. [PubMed: 27759965]

95. Spataro R, Ficano L, Piccoli F, La Bella V. Percutaneous endoscopic gastrostomy in amyotrophic lateral sclerosis: effect on survival. J Neurol Sci. 2011; 304(1-2):44-48. doi:http://dx.doi.org/ 10.1016/j.jns.2011.02.016. [PubMed: 21371720]

96. Johnson J, Leigh PN, Shaw CE, Ellis C, Burman R, Al-Chalabi A. Eating-derived pleasure in amyotrophic lateral sclerosis as a predictor of non-oral feeding. Amyotroph. 2012; 13(6):555-559. doi:http://dx.doi.org/10.3109/17482968.2012.704925.

97. Wilson PS, Bruce-Lockhart FJ, Johnson AP. Videofluoroscopy in motor neurone disease prior to cricopharyngeal myotomy. Ann R Coll Surg Engl. 1990; 72(6):375-377. [PubMed: 2241057]

98. Benditt JO. Respiratory complications of amyotrophic lateral sclerosis. Semin. 2002; 23(3):239247.

99. Wijesekera LC, Leigh PN. Amyotrophic lateral sclerosis. Orphanet Journal of Rare Diseases. 2009; 4(1) doi:http://dx.doi.org/10.1186/1750-1172-4-3.

100. Palovcak M, Mancinelli JM, Elman LB, McCluskey L. Diagnostic and therapeutic methods in the management of dysphagia in the ALS population: issues in efficacy for the out-patient setting. NeuroRehabilitation. 2007; 22(6):417-423. [PubMed: 18198426]

101. Luchesi KF, Kitamura S, Mourao LF. Management of dysphagia in Parkinson's disease and amyotrophic lateral sclerosis. CoDAS. 2013; 25(4):358-364. [PubMed: 24408486]

102. Escuro AA. Nutrition support in amyotrophic lateral sclerosis: from diagnosis through terminal phase. Support Line. 2012; 34(2):8-19. 10.

103. Greenwood DI. Nutrition management of amyotrophic lateral sclerosis. Nutr Clin Pract. 2013; 28(3):392-399. doi:http://dx.doi.org/10.1177/0884533613476554. [PubMed: 23466470]

104. Heffernan C, Jenkinson C, Holmes T, Feder G, Kupfer R, Leigh PN, McGowan S, Rio A, Sidhu P. Nutritional management in MND/ALS patients: an evidence based review. Amyotroph Lateral Scler Other Motor Neuron Disord. 2004; 5(2):72-83. [PubMed: 15204009]

105. Hillel AD, Miller R. Bulbar amyotrophic lateral sclerosis: patterns of progression and clinical management. Head Neck. 1989; 11(1):51-59. [PubMed: 2921111]

106. Procaccini NJ, Nemergut EC. Percutaneous endoscopic gastrostomy in the patient with amyotrophic lateral sclerosis: Risk vs benefit? Practical Gastroenterology. 2008; 32(3):24-34.

107. Scott AG, Austin HE. Nasogastric feeding in the management of severe dysphagia in motor neurone disease. Palliat Med. 1994; 8(1):45-49. [PubMed: 8180740]

108. Silani V, Kasarskis EJ, Yanagisawa N. Nutritional management in amyotrophic lateral sclerosis: a worldwide perspective. J Neurol. 1998; 245(Suppl 2):S13-19. discussion S29. [PubMed: 9747929] 
109. Stavroulakis T, Baird WO, Baxter SK, Walsh T, Shaw PJ, McDermott CJ. Factors influencing decision-making in relation to timing of gastrostomy insertion in patients with motor neurone disease. BMJ support. 2014; 4(1):57-63. doi:http://dx.doi.org/10.1136/bmjspcare-2013-000497.

110. Stavroulakis T, Walsh T, Shaw PJ, McDermott CJ, Progas S. Gastrostomy use in motor neurone disease (MND): a review, meta-analysis and survey of current practice. Amyotroph Lateral Scler Frontotemporal Degener. 2013; 14(2):96-104. doi:http://dx.doi.org/ 10.3109/17482968.2012.723722. [PubMed: 22985431]

111. Perry A, Anderson K, Lean R, Cotton S. Elevation of the soft palate in speech and swallowing in normal female participants and females with motor neuron disease: an innovative procedure for measuring palatal elevation. Int J Lang Commun Disord. 2002; 37(2):197-214. [PubMed: 12012616]

112. Jesus P, Massoulard A, Marin B, Nicol M, Laplagne O, Baptiste A, Gindre-Poulvelarie L, Couratier P, Fraysse JL, Desport JC. First assessment at home of amyotrophic lateral sclerosis (ALS) patients by a nutrition network in the French region of Limousin. Amyotroph. 2012; 13(6):538-543. doi:http://dx.doi.org/10.3109/17482968.2012.701309.

113. Corcia P, Meininger V. Management of amyotrophic lateral sclerosis. Drugs. 2008; 68(8):10371048. [PubMed: 18484797]

114. Elman LB, Houghton DJ, Wu G, Hurtig HI, Markowitz CE, McCluskey L. Palliative care in amyotrophic lateral sclerosis, Parkinson's disease, and multiple sclerosis. Journal of Palliative Medicine. 2007; 10(2):433-457. doi:http://dx.doi.org/10.1089/jpm.2006.9978. [PubMed: 17472516]

115. Kosseifi SG, Abdel Nour S, Roy TM, Byrd RP Jr, Alwani A. Respiratory failure in a 70-year-old veteran. South Med J. 2010; 103(4):378-381. doi:http://dx.doi.org/10.1097/SMJ. 0b013e3181d3ceaa. [PubMed: 20224486]

116. Kidney D, Alexander M, Corr B, O’Toole O, Hardiman O. Oropharyngeal dysphagia in amyotrophic lateral sclerosis: neurological and dysphagia specific rating scales. Amyotroph Lateral Scler Other Motor Neuron Disord. 2004; 5(3):150-153. [PubMed: 15512903]

117. Dworkin JP, Hartman DE. Progressive speech deterioration and dysphagia in amyotrophic lateral sclerosis: case report. Arch Phys Med Rehabil. 1979; 60(9):423-425. [PubMed: 496610]

118. Hansen A, Bedore B, Nickel E, Hanowski K, Tangen S, Goldish G. Elastic head support for persons with amyotrophic lateral sclerosis. J Rehabil Res Dev. 2014; 51(2):297-303. doi:http:// dx.doi.org/10.1682/JRRD.2013.03.0072. [PubMed: 24933727]

119. Walshe M. Oropharyngeal dysphagia in neurodegenerative disease. Journal of Gastroenterology and Hepatology Research. 2014; 3(10):1265-1271. doi:http://dx.doi.org/10.6051/j.issn. 2224-3992.2014.03.408-2.

120. Plowman EK. Is there a role for exercise in the management of bulbar dysfunction in amyotrophic lateral sclerosis? Journal of Speech, Language, and Hearing Research. 2015; 58(4):1151.

121. Robison, R. Thesis. University of South Florida; 2015. The impact of lingual resistance training in two individuals with Amyotrophic Lateral Sclerosis: a case series.

122. Goeleven A, Robberecht W, Sonies B, Carbonez A, Dejaeger E. Manofluorographic evaluation of swallowing in amyotrophic lateral sclerosis and its relationship with clinical evaluation of swallowing. Amyotrophic lateral sclerosis: official publication of the World Federation of Neurology Research Group on Motor Neuron Diseases. 2006; 7(4):235-240. DOI: $10.1080 / 17482960600664870$

123. Mayberry JF, Atkinson M. Swallowing problems in patients with motor neuron disease. Journal of Clinical Gastroenterology. 1986; (8):233-234. [PubMed: 3734354]

124. Isaacs JD, Dean AF, Shaw CE, Al-Chalabi A, Mills KR, Leigh PN. Amyotrophic lateral sclerosis with sensory neuropathy: part of a multisystem disorder? Journal of Neurology, Neurosurgery, and Psychiatry. 2007; 78(7):750-753. DOI: 10.1136/jnnp.2006.098798

125. Setzen M, Cohen MA, Perlman PW, Belafsky PC, Guss J, Mattucci KF, Ditkoff M. The association between laryngopharyngeal sensory deficits, pharyngeal motor function, and the prevalence of aspiration with thin liquids. Otolaryngology - Head and Neck Surgery. 2003; 128(1):99-102. [PubMed: 12574766] 
126. Aviv JE, Sacco RL, Mohr JP, Thompson JL, Levin B, Sunshine S, Thomson J, Close LG. Laryngopharyngeal sensory testing with modified barium swallow as predictors of aspiration pneumonia after stroke. Laryngoscope. 1997; 107(9):1254-1260. [PubMed: 9292613]

127. Rodriguez de Rivera FJ, Oreja Guevara C, Sanz Gallego I, San Jose Valiente B, Santiago Recuerda A, Gomez Mendieta MA, Arpa J, Diez Tejedor E. Outcome of patients with amyotrophic lateral sclerosis attending in a multidisciplinary care unit. Neurologia. 2011; 26(8): 455-460. doi:http://dx.doi.org/10.1016/j.nrl.2011.01.021. [PubMed: 21419529]

128. Sancho J, Servera E, Díaz J, Marín J. Efficacy of Mechanical Insufflation-Exsufflation in Medically Stable Patients With Amyotrophic Lateral Sclerosis. Chest. 2004; 125(4):1400-1405. doi:https://doi.org/10.1378/chest.125.4.1400. [PubMed: 15078752]

129. Sancho J, Servera E, Díaz J, Marín J. Predictors of Ineffective Cough during a Chest Infection in Patients with Stable Amyotrophic Lateral Sclerosis. American Journal of Respiratory and Critical Care Medicine. 2007; 175(12):1266-1271. DOI: 10.1164/rccm.200612-1841OC [PubMed: 17413124]

130. Miller RG, Jackson CE, Kasarskis EJ, England JD, Forshew D, Johnston W, Kalra S, Katz JS, Mitsumoto H, Rosenfeld J, Shoesmith C, Strong MJ, Woolley SC. Practice Parameter update: The care of the patient with amyotrophic lateral sclerosis: Multidisciplinary care, symptom management, and cognitive/behavioral impairment (an evidence-based review): Report of the Quality Standards Subcommittee of the American Academy of Neurology. Neurology. 2009; 73(15):1227-1233. [PubMed: 19822873]

131. Britton D, Benditt JO, Merati AL, Miller RM, Stepp CE, Boitano L, Hu A, Ciol MA, Yorkston KM. Associations between laryngeal and cough dysfunction in motor neuron disease with bulbar involvement. Dysphagia. 2014; 29(6):637-646. doi:http://dx.doi.org/10.1007/ s00455-014-9554-5. [PubMed: 25037590] 


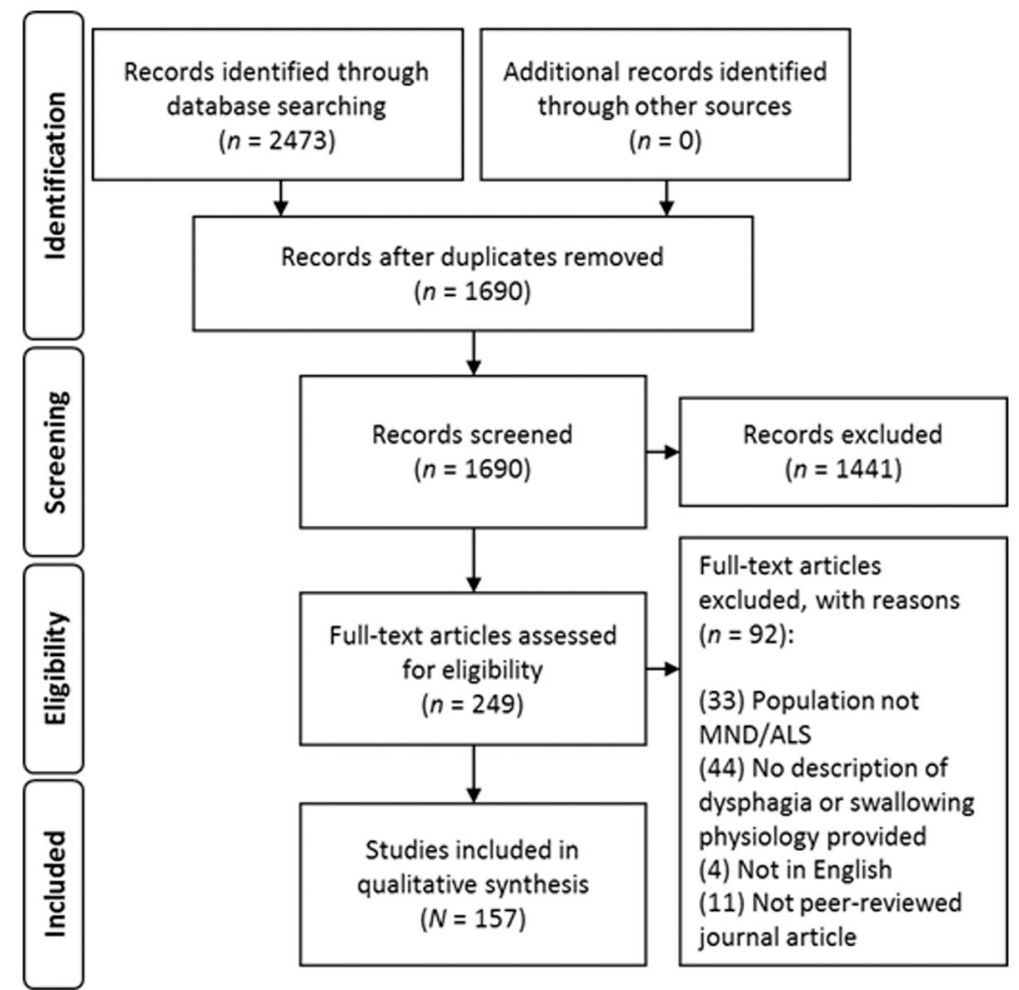

Figure 1. 


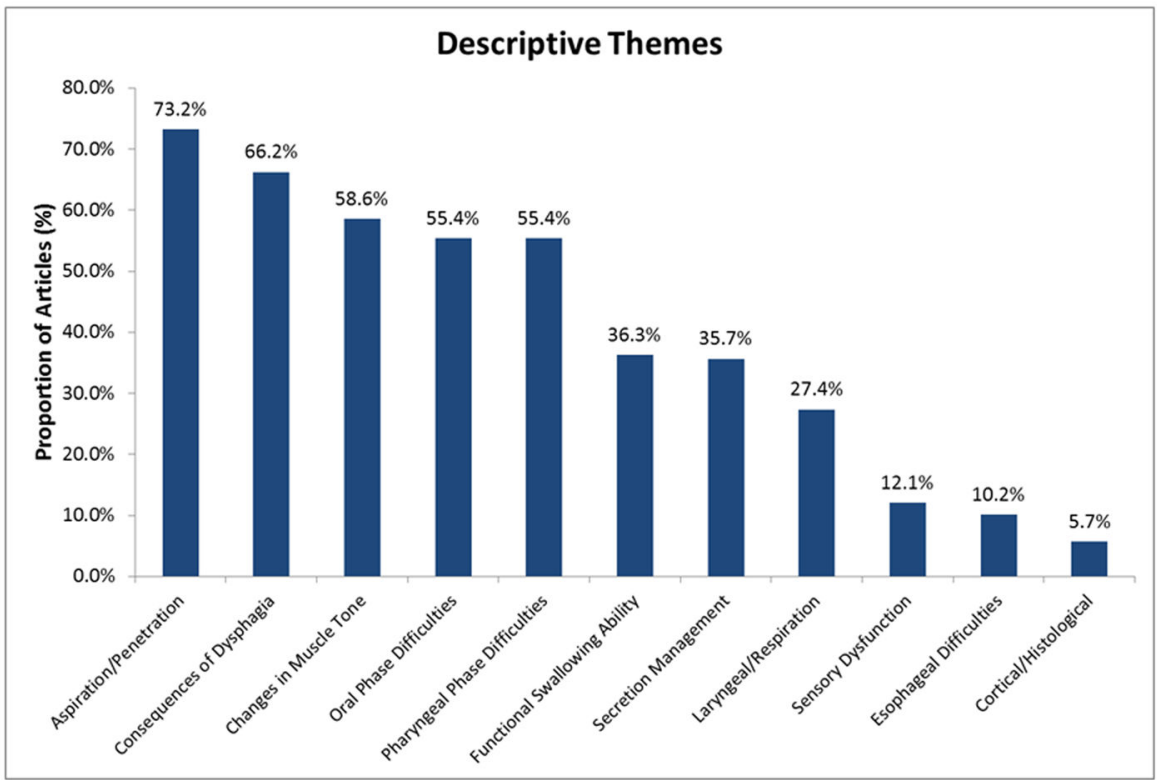

Figure 2. 


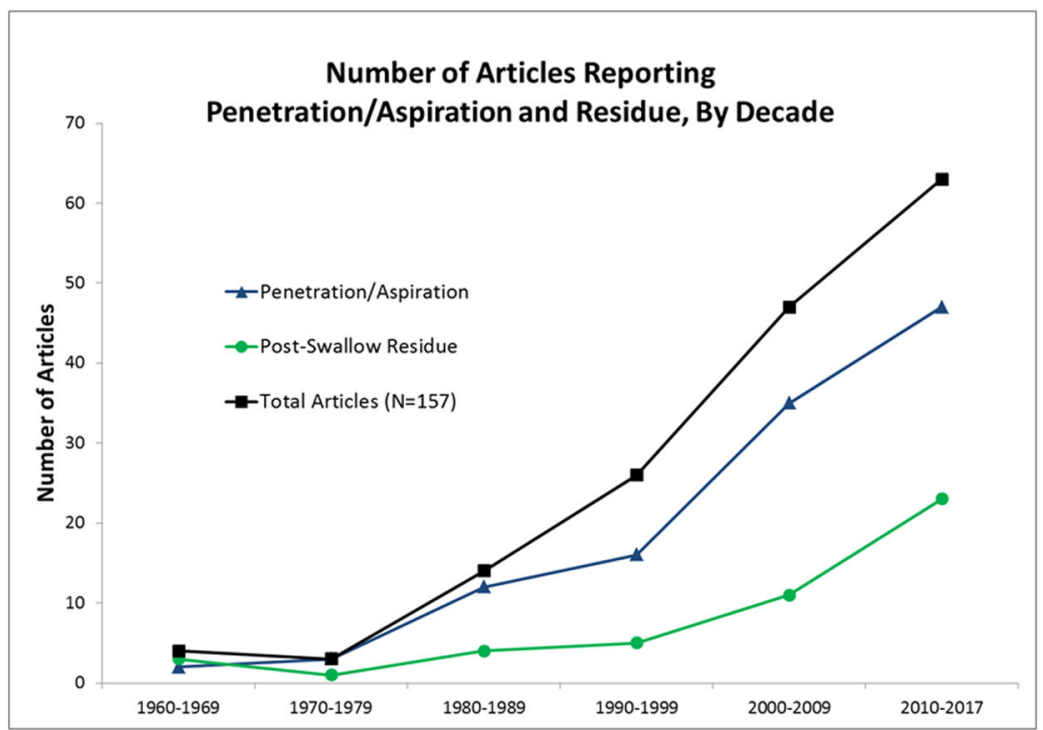

Figure 3. 


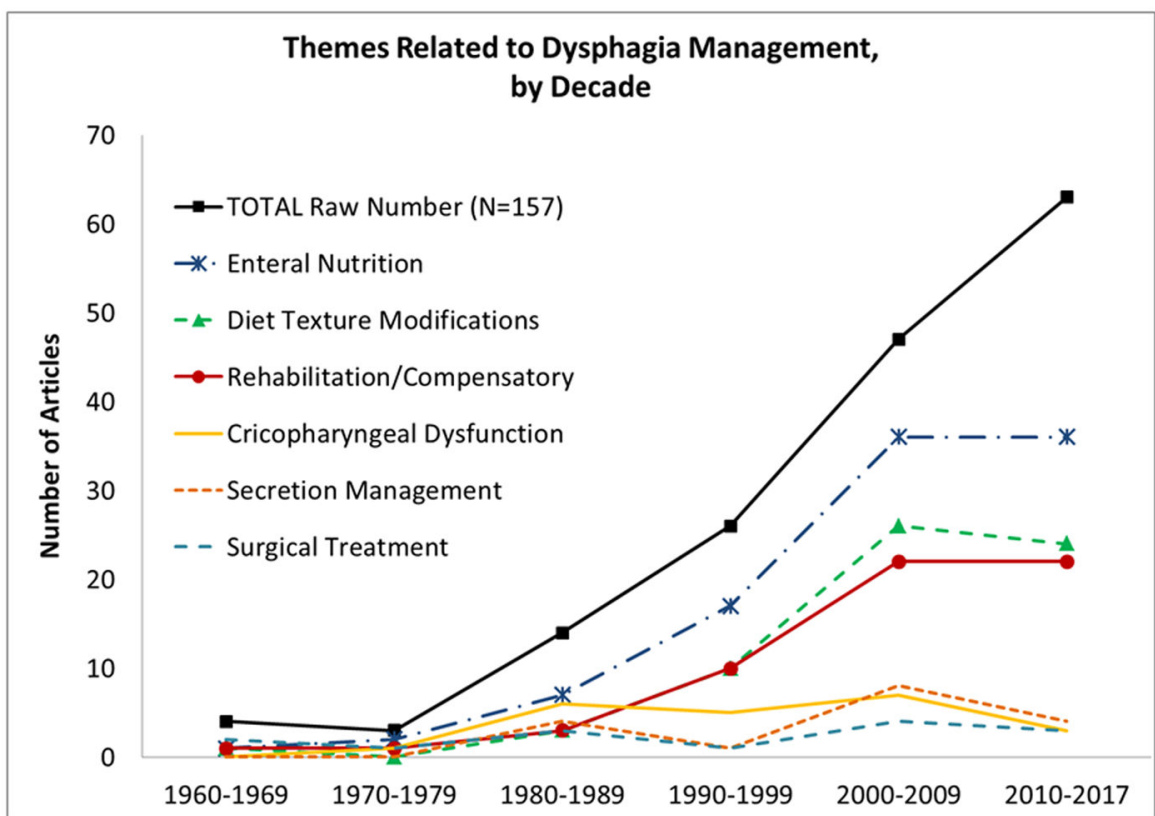

Figure 4. 


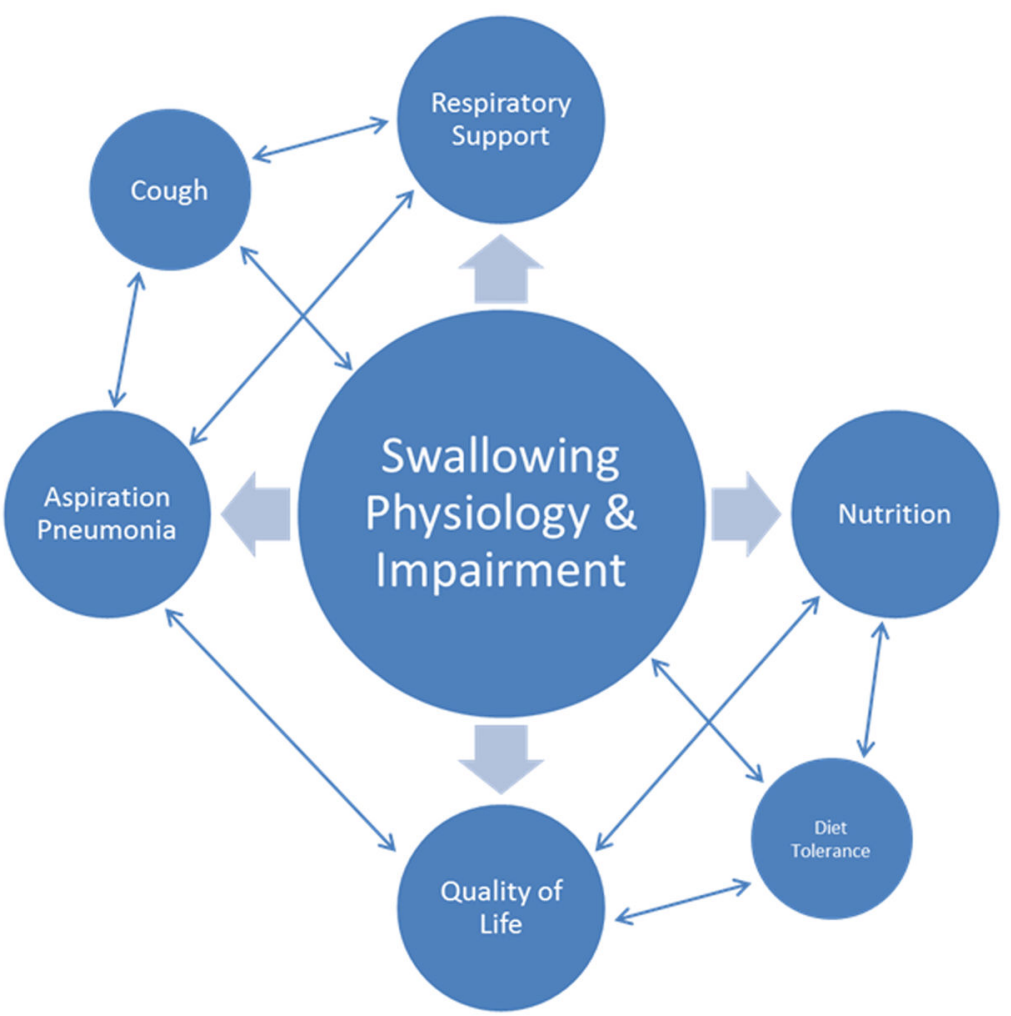

Figure 5. 


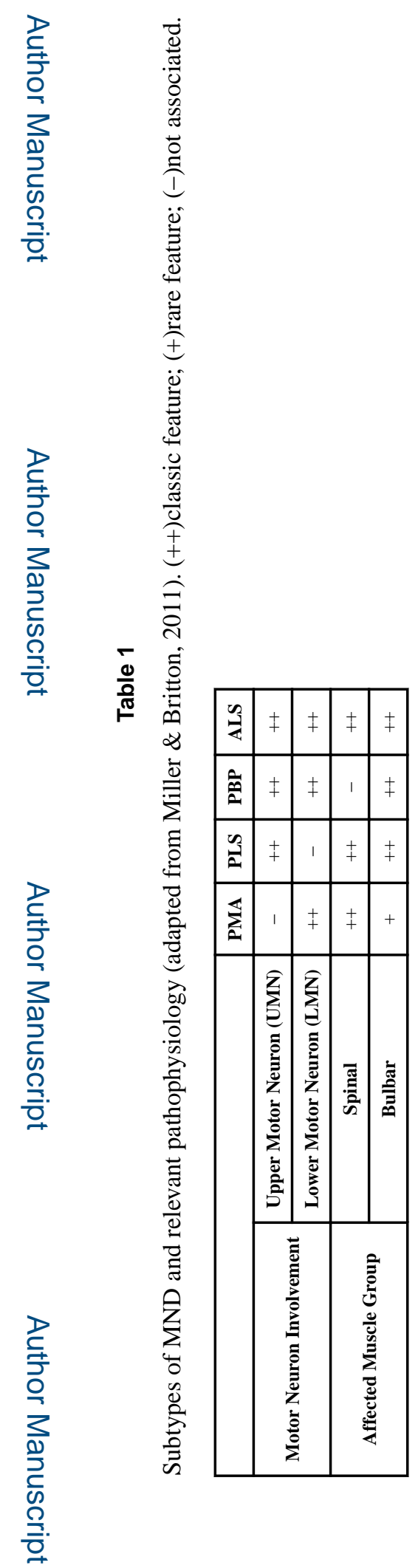

Dysphagia. Author manuscript; available in PMC 2018 December 01. 


\section{Table 2}

Agreement statistics for theme tabulation. Qualitative agreement based on Kappa statistic [25].

\begin{tabular}{|lccc|}
\hline & \% Agree & Kappa & Agreement \\
\hline ALL THEMES (TOTAL) & $\mathbf{8 7 . 2 3}$ & $\mathbf{0 . 6 4 6}$ & Substantial \\
Penetration/Aspiration & 89.29 & 0.512 & Moderate \\
Oral Phase & 89.29 & 0.781 & Substantial \\
Pharyngeal Phase & 78.57 & 0.543 & Moderate \\
Laryngeal/Respiration & 78.57 & 0.475 & Moderate \\
Esophageal Phase & 85.71 & 0.291 & Fair \\
Dysphagia Consequences & 92.86 & 0.837 & Substantial \\
Functional Ability & 92.86 & 0.850 & Substantial \\
Altered Muscle Tone & 82.14 & 0.620 & Substantial \\
\hline
\end{tabular}


Table 3

\begin{tabular}{|c|c|c|c|}
\hline \multirow{7}{*}{ 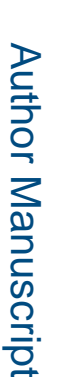 } & Summary of article char & cteristics, al & studie \\
\hline & & Raw Number & $(\%)$ \\
\hline & \multicolumn{3}{|l|}{ Location/Origin } \\
\hline & United States & 51 & $32.5 \%$ \\
\hline & United Kingdom & 34 & $21.7 \%$ \\
\hline & Italy & 15 & $9.6 \%$ \\
\hline & Japan & 14 & $8.9 \%$ \\
\hline \multirow{13}{*}{ 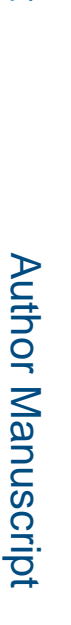 } & Australia & 7 & $4.5 \%$ \\
\hline & France & 6 & $3.8 \%$ \\
\hline & Brazil & 6 & $3.8 \%$ \\
\hline & Turkey & 5 & $3.2 \%$ \\
\hline & Canada & 4 & $2.5 \%$ \\
\hline & Germany & 3 & $1.9 \%$ \\
\hline & Korea & 2 & $1.3 \%$ \\
\hline & Spain & 2 & $1.3 \%$ \\
\hline & Poland & 2 & $1.3 \%$ \\
\hline & Portugal & 2 & $1.3 \%$ \\
\hline & Belgium & 1 & $0.6 \%$ \\
\hline & China & 1 & $0.6 \%$ \\
\hline & Netherlands & 1 & $0.6 \%$ \\
\hline \multirow{11}{*}{ 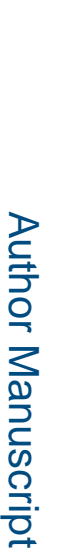 } & Article Type & & \\
\hline & Review & 34 & $21.7 \%$ \\
\hline & Non-Review & 123 & $78.3 \%$ \\
\hline & -Observational & 112 & $71.3 \%$ \\
\hline & -Experimental & 8 & $5.1 \%$ \\
\hline & -Animal & 3 & $1.9 \%$ \\
\hline & \multicolumn{3}{|l|}{ MND-Type } \\
\hline & $A L S$ & 111 & $69.4 \%$ \\
\hline & $M N D$ (unspecified/mixed) & 39 & $24.8 \%$ \\
\hline & $P B P$ & 4 & $2.5 \%$ \\
\hline & SOD1 (animal model) & 3 & $1.9 \%$ \\
\hline & $P L S$ & 2 & $1.3 \%$ \\
\hline
\end{tabular}

로을

Dysphagia. Author manuscript; available in PMC 2018 December 01. 


\section{Table 4}

Summary of tools and analyses used in studies with instrumental assessment $(n=71)$.

\begin{tabular}{|lcc|}
\hline \multicolumn{2}{|c|}{ Raw Number of Articles } & Proportion (\%) \\
\hline Instrumentation Type & & $70.4 \%$ \\
Radiographic & 50 & $25.4 \%$ \\
Endoscopy & 10 & $15.5 \%$ \\
Manometry & 11 & $11.3 \%$ \\
EMG & 8 & $21.1 \%$ \\
Other & 17 & \\
Simultaneous Tools & & $64.8 \%$ \\
One & 46 & $28.2 \%$ \\
Two & 21 & $5.6 \%$ \\
Three & 4 & $4.2 \%$ \\
Four & 1 & \\
Instrumentation Analysis & & $47.9 \%$ \\
Descriptive & 34 & $19.7 \%$ \\
Quantitative & 15 & $23.9 \%$ \\
Combination & 17 & $7.0 \%$ \\
Not Presented & 5 & \\
\hline
\end{tabular}

로을

Dysphagia. Author manuscript; available in PMC 2018 December 01. 